Research Article

\title{
A Study to Assess the Unmet Needs of Family Planning and Reason for Non-Use of Contraceptive Methods among Women in Reproductive Age Group in a Selected Community in West Bengal
}

\author{
Arpita Banerjee $^{1}, \underline{\text { Sabitri Kuila }}{ }^{2}$ \\ ${ }^{1}$ Post Graduate Student, ${ }^{2}$ Vice Principle, Obstetrics and Gynaecology, Apollo Gleneagles Nursing College, Kolkata, India. \\ DOI: https://doi.org/10.24321/2348.2133.202002
}

I $\quad \mathbf{N} \quad \mathbf{F} \quad \mathbf{O}$

Corresponding Author:

Arpita Banerjee, Obstetrics and Gynaecology, Apollo Gleneagles Nursing College, Kolkata, India.

E-mail Id:

arpita.banerjee0301@gmail.com

Orcid Id:

https://orcid.org/0000-0002-3398-9615

How to cite this article:

Banerjee A, Kuila S. A Study to Assess the Unmet Needs of Family Planning and Reason for Non-Use of Contraceptive Methods among Women in Reproductive Age Group in a Selected Community in West Bengal. Ind J Holist Nurs 2020; 11(3): 6-11.

Date of Submission: 2021-01-19

Date of Acceptance: 2021-02-25
$\begin{array}{llllllll}\mathbf{A} & \mathbf{B} & \mathbf{S} & \mathbf{T} & \mathbf{R} & \mathbf{A} & \mathbf{C} & \mathbf{T}\end{array}$

Background: A comparative descriptive study to assess unmet needs of family planning and reason for non-use of contraceptiveswhere non-probability purposive sampling technique was used to select 200 reproductive age group women i.e. 100 from urban and 100 from rural community.

Methods: Data was collected through self- structured interview schedule through home visits.The majorfindings of the study showed that unmet needs of family planning were $38 \%$ in urban and $27 \%$ in rural women.

Result: The common reasons for non-use of contraceptives were fertility related reasons i.e. $42.1 \%$ women had desire for more children in urban versus $37.03 \%$ of women reported for infrequent sex in rural. Respondent's restriction was $42.1 \%$ in urban and $40.7 \%$ in rural. Fear of side effects like health problems were $26.3 \%$ in urban women versus $22.22 \%$ in rural. Contraceptive method related reasons were in $15.8 \%$ urban women who reported interference with body process with previous usage versus $33.3 \%$ in rural. Unawareness was in $15.8 \%$ urban women and $7.40 \%$ in rural women. Misperception like IUD penetrates uterus was $2.6 \%$ in urban women and $11.11 \%$ in rural. Non- utilization of health care services was $2.6 \%$ in urban community whereas $33.3 \%$ in rural. The study showed no significant association between age and respondent's restriction, desire for more children and infrequent sex and background information i.e. age and religion in both communities. Conclusion: The study showed that awareness and usage of contraceptives in rural areas was more as compared to urban areas.

Keywords: Unmet Needs, Family Planning, Reasons, Contraceptive Methods, Reproductive Age Group, Community 


\section{Introduction}

Unmet need for family planning which refers to the condition in which there is the desire to avoid or post-pone child bearing, without the use of any means of contraception. ${ }^{1}$ Unmet needs for contraception are the percentage of fertile, married women of reproductive age who do not want to become pregnant and are not using contraception. ${ }^{2}$ The concept of unmet needs points to the gap between women's reproductive intentions and their contraceptive behaviour. ${ }^{3}$

The study objectives were to assess the unmet needs of family planning and the reasons for non-use of contraceptive methods and to find association between reasons and background information among women in reproductive age group in a selected urban and rural community in West Bengal. The conceptual framework of this study was based on Rosenstock and Becker's 'Health Belief Model'.

According to the World Health Organisation, it has been estimated that 210 million women get pregnant every year, and only, two-third of them deliver live infants. The rest one-third ends in stillbirths, miscarriage, and abortion. Family planning has reduced the number of unwanted and unintended pregnancies and thereby saving women from high-risk pregnancies and unsafe abortions. It has been reported from India that use of oral contraceptives is less because of social taboos and beliefs.

Unplanned pregnancy poses a major health challenge to women of reproductive age especially in developing countries. It has been estimated that about 80 million (38\%) of the 210 million pregnancies that occur annually worldwide, are unplanned, and about 46 million (22\%) end up in abortion.4 An unwanted sex and non-use of contraceptive method leads to unwanted pregnancy thus creating a scenario of unmet needs. Abortion in majority of the government hospitals are performed in unhygienic and less equipped surroundings where more chances of infection through the reproductive tract is present. An infection might also be life threatening resulting in maternal death. Otherwise repeated pregnancies will ultimately lead to increased family size. More number of family members with limited income will again give birth to other problems related to children's education, nourishment, health problems etc. Also, there are various reasons towards not using contraceptives due to personal or societal beliefs. Thus, a planned pregnancy and childbirth has got better outcomes than the unplanned ones.

A community based cross sectional study was conducted to assess the unmet need for family planning for 6 months among 1600 married women of reproductive age group of 15-49 years in the urban and rural field practice area under Department of Community Medicine, Indira Gandhi
Medical College and Hospital Shimla, India. The outcomes showed that unmet needs for family planning were $11.5 \%$ and $8.8 \%$ in rural and urban area, respectively. Unmet needs were highest among age group less than 20 years (38.2\%) followed by age group $21-25$ years (20.4\%). Education level has been found significantly associated with unmet needs. Unmet needs were highest among illiterate women (26.3\%) in the current study. Unmet need for family planning among homemakers (11.6\%) was found significantly higher. ${ }^{5}$

Unmet needs for family planning is a valuable concept that is widely used for advocacy, development of family planning policies, implementation and monitoring of family planning programmes worldwide. ${ }^{6}$

The unmet need for family planning is a very useful tool in measuring and predicting the contraceptive needs of a population. Family planning is one of the fundamental pillars of safe motherhood and a reproductive right. The practice of family planning is influenced by several socio-demographic factors, hence its variation between regions of the world, countries and within countries. It is pertinent to reposition family planning to accelerate the reductionof maternal and neonatal mortality in less developed countries. ${ }^{7}$

\section{Methodology}

A non-experimental research approach with comparative descriptive research design was adopted for the study. The present study was conducted at selected urban community of Jyotinagar and rural community of Reckjoani among 200 reproductive age group women using non-probability purposive sampling technique. The inclusion criteria were to include the willing reproductive age group women who were married and sexually active and who can understand Hindi/ English/ Bangla with written informed consent. Study duration was one month $\left(1^{\text {st }}\right.$ December, 2019- $31^{\text {st }}$ December 2019). The study synopsis was approved by the Institutional Ethics Committee of Apollo Gleneagles Hospital, Kolkata. Permission from Directorate of health services, Swasthya Bhawan; $\mathrm{CMOH}$, Barasat and $\mathrm{CMO}$, Puoro Bhawan was received. Validated and Reliable tool computed by Interrater method with coefficient value as 0.82 was used. Data related to background information was collected by structured interview schedule for all reproductive age group women. Interview schedule on reasons for non-use of contraceptives was gathered from the women who had unmet needs of family planning with the help of home visits.

\section{Result}

In this study the result showed that the unmet needs were $38 \%$ in urban women and $27 \%$ in rural women. 


\begin{tabular}{|lr}
\hline & \\
& $\mathbf{4 0}$ \\
$\mathbf{E}$ & $\mathbf{3 5}$ \\
$\mathbf{R}$ & $\mathbf{3 0}$ \\
$\mathbf{C}$ & $\mathbf{2 5}$ \\
$\mathbf{E}$ & \\
$\mathbf{N}$ & $\mathbf{2 0}$ \\
$\mathbf{T}$ & $\mathbf{1 5}$ \\
$\mathbf{A}$ & $\mathbf{6}$ \\
$\mathbf{G}$ & $\mathbf{1 0}$ \\
$\mathbf{E}$ & $\mathbf{5}$ \\
& $\mathbf{0}$
\end{tabular}
38

Unmet needs of family planning

Urban

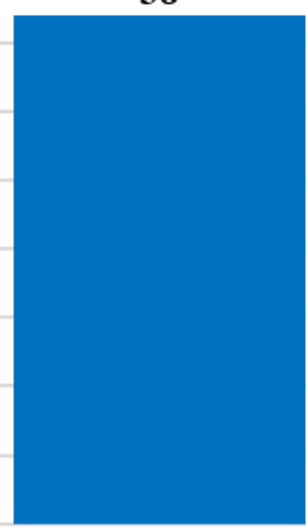

27

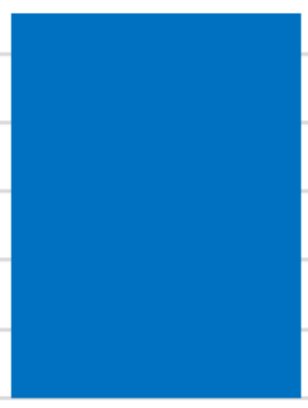

Rural

Figure I.Distribution of unmet needs of family planning

Table I.Frequency and percentage distribution of reasons according to rank order in the urban community

\begin{tabular}{|c|c|c|c|}
\hline Reasons & $\begin{array}{c}\text { Response } \\
\text { Frequency (f) }\end{array}$ & $\begin{array}{c}\text { Response } \\
\text { percentage (\%) }\end{array}$ & $\begin{array}{c}\text { Respondent's } \\
\text { percentage (\%) }\end{array}$ \\
\hline \multicolumn{4}{|l|}{ Fertility related } \\
\hline Desire for more children & 16 & 42.1 & 16.8 \\
\hline Infrequent sex & 14 & 36.8 & 14.7 \\
\hline Breastfeeding & 8 & 21.1 & 8.4 \\
\hline Postpartum amenorrhoeic & 3 & 7.9 & 3.15 \\
\hline \multicolumn{4}{|l|}{ Restriction to use } \\
\hline Respondents restriction & 16 & 42.1 & 16.8 \\
\hline Husband's restriction & 7 & 18.4 & 7.4 \\
\hline Others restriction (Mother, Sister-in law) & 1 & 2.6 & 1.05 \\
\hline \multicolumn{4}{|l|}{ Fear of side effects } \\
\hline Health problems (headache, nausea, etc.) & 10 & 26.3 & 10.5 \\
\hline Weight gain, high BP, Depression & 3 & 7.9 & 3.15 \\
\hline Low backache & 1 & 2.6 & 1.05 \\
\hline \multicolumn{4}{|l|}{ Contraceptive method related } \\
\hline Interference with body process with previous usage & 6 & 15.8 & 6.31 \\
\hline Contraceptives are inconvenient to use & 1 & 2.6 & 1.05 \\
\hline \multicolumn{4}{|l|}{ Awareness } \\
\hline No sources of information & 6 & 15.8 & 6.31 \\
\hline \multicolumn{4}{|l|}{ Misperception } \\
\hline IUD penetrates uterus and travels to other organs. & 1 & 2.6 & 1.05 \\
\hline \multicolumn{4}{|l|}{ Non-utilization of health care services } \\
\hline Far distance from home & 1 & 2.6 & 1.05 \\
\hline No time to go health care facility & 1 & 2.6 & 1.05 \\
\hline Total & 95 & 249.8 & 99.82 \\
\hline
\end{tabular}

* There were multiple reasons from the participants. 
Table 2.Frequency and percentage distribution of reasons according to rank order in the rural community

\begin{tabular}{|c|c|c|c|}
\hline Reasons & $\begin{array}{c}\text { Response } \\
\text { Frequency (f) }\end{array}$ & $\begin{array}{c}\text { Response } \\
\text { percentage (\%) }\end{array}$ & $\begin{array}{c}\text { Respondent's } \\
\text { percentage (\%) }\end{array}$ \\
\hline \multicolumn{4}{|l|}{ Restriction to use } \\
\hline Respondents restriction & 11 & 40.7 & 11.7 \\
\hline Husband's restriction & 4 & 14.8 & 4.2 \\
\hline Others restriction (Mother, Sister-in-law) & 3 & 11.11 & 3.2 \\
\hline Religious prohibition & 1 & 3.70 & 1.06 \\
\hline \multicolumn{4}{|l|}{ Fertility related } \\
\hline Infrequent sex & 10 & 37.03 & 10.6 \\
\hline Breastfeeding & 10 & 37.03 & 10.6 \\
\hline Postpartum amenorrhoeic & 8 & 29.6 & 8.5 \\
\hline Desire for more children & 8 & 29.6 & 8.5 \\
\hline \multicolumn{4}{|l|}{ Contraceptive method related } \\
\hline Interference with body process with previous usage & 9 & 33.3 & 9.6 \\
\hline Contraceptives are inconvenient to use & 2 & 7.4 & 2.12 \\
\hline \multicolumn{4}{|l|}{ Non-utilization of health care services } \\
\hline No time to go health care facility & 9 & 33.3 & 9.6 \\
\hline Far distance from home & 2 & 7.40 & 2.12 \\
\hline \multicolumn{4}{|l|}{ Fear of side effects } \\
\hline Health problems (headache, nausea, etc) & 6 & 22.22 & 6.4 \\
\hline Weight gain, high BP, Depression, Obesity & 3 & 11.11 & 3.2 \\
\hline \multicolumn{4}{|l|}{ Misperception } \\
\hline IUD penetrates uterus & 3 & 11.11 & 3.2 \\
\hline Contraceptives harms existing pregnancy & 2 & 7.40 & 2.12 \\
\hline Contraceptives pill are abortion pill & 1 & 3.70 & 1.06 \\
\hline \multicolumn{4}{|l|}{ Awareness } \\
\hline No sources of information & 2 & 7.40 & 2.12 \\
\hline Total & 94 & 347.91 & 99.9 \\
\hline
\end{tabular}

*There were multiple reasons from the participants.

From Figure 1, it is revealed that the unmet needs of family planning were $38 \%$ in the urban and $27 \%$ in rural reproductive age group women.

Data presented in Table 1, revealed the reasons for non-use of contraceptives were $42.1 \%$ urban women had desire for more children; $42.1 \%$ had respondent's restriction; $26.3 \%$ women had fear of side effects like health problems in urban community; $15.8 \%$ reported interference with body process with previous usage; $15.8 \%$ urban women had no sources of information; $2.6 \%$ reported IUD penetrates uterus and also $2.6 \%$ had reasons related to non-utilization of health care services.

Data in Table 2, depicted the common reasons behind non-use of contraceptives i.e. $40.7 \%$ rural women had respondent's restriction; $37.03 \%$ of women reported for infrequent sex and also $37.03 \%$ were breastfeeding; $33.3 \%$ women had interference with body process with previous usage in the rural community. $33.3 \%$ of women reported reasons related to non-utilization of health care services; $22.22 \%$ rural women had fear of side effects like health problems; $11.11 \%$ reported IUD penetrates uterus and $7.40 \%$ reported that they had no sources of information.

Data in Figure 2, showed that $15.80 \%$ urban women and $7.40 \%$ rural women were unaware regarding contraceptives; $42.10 \%$ urban women and $40.70 \%$ rural women had restriction to use; $44.70 \%$ urban women and $37.03 \%$ rural 
women had fertility related reasons; $15.80 \%$ urban women and $33.30 \%$ rural women had contraceptive method related reasons; $2.60 \%$ urban women and $11.11 \%$ rural women had misperception; $2.60 \%$ urban women and $33.30 \%$ rural women had non-utilization of health care services.
$26-35$ years i.e. $(42.10 \%)$ in urban and $(29.62 \%)$ in rural. The findings of the present study were supported by another study conducted by Sachdeva A, Gupta A, Kumar D, Singh $\mathrm{H}$, Sharma $\mathrm{S}$. to assess unmet needs of family planning in urban and rural areas of Shimla. The findings of the study

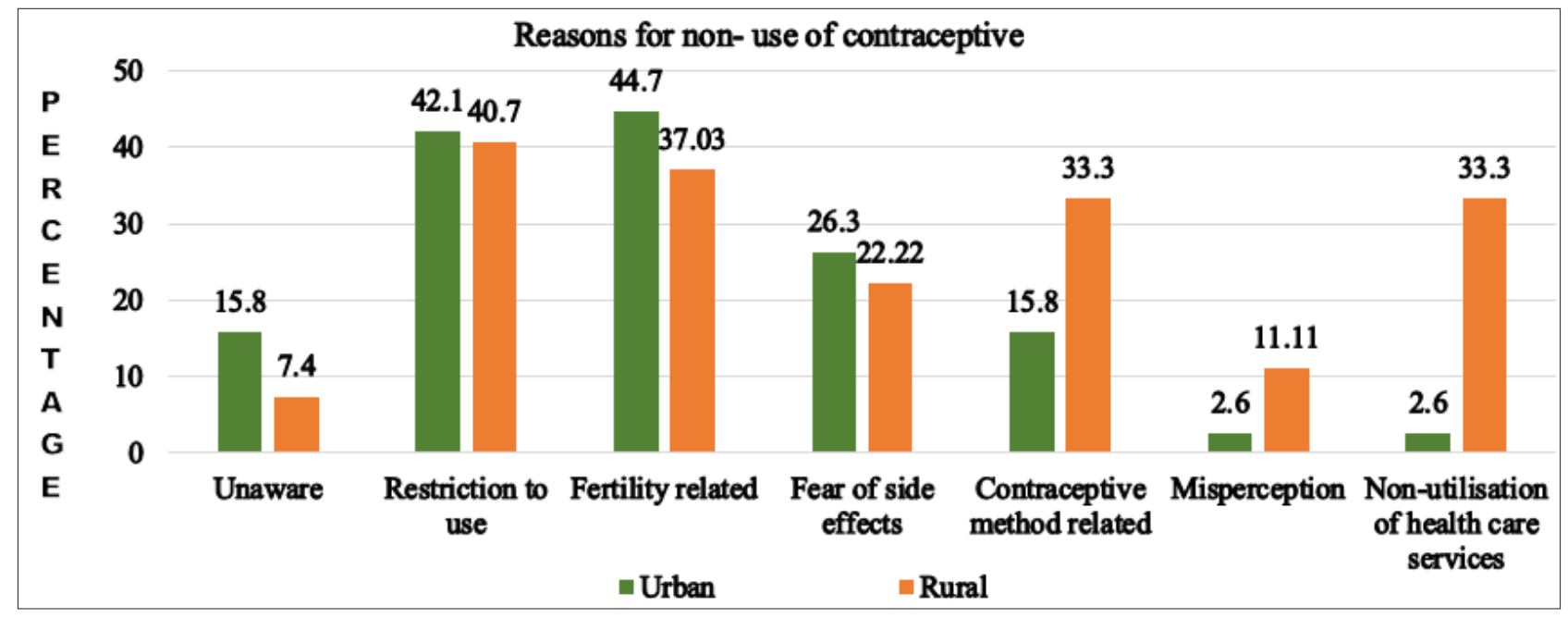

Figure 2.Description regarding comparison of reasons who had unmet needs of family planning in urban and rural community

\section{Discussion}

The present study utilized seven broad areas in order to gather data on reasons for non-use of contraceptives like fertility related reasons like desire for more children (44.7\%); restriction like respondent's as (42.1\%); fear of side effects like health problems (26.3\%); contraceptive method related like interference with the body processes (15.8\%) same as of misperceptions and health care services related reasons like no time to go health care facility (2.6\%)in the urban community.The findings of the present study were supported by another study conducted by D Sudarshan, T Ratikanta, T Bhaskar, P Suresh, S Pushpam, M Manjushree. to observe the pattern of unmet need of contraceptive use in married couples at KIMS, Orrisa. The study revealed that reason for not using contraceptives was to get a child (49.2\%) and also due to side effects (29\%). ${ }^{3}$

The present study showed that among 200 reproductive age group women i.e.100 in each setting, as per interview $38 \%$ women in urban and $27 \%$ in rural community had unmet needs of family planning. The findings of the present study were supported by another study conducted by F Rujuta, $\mathrm{S}$ Neelam. to assess the differences in unmet needs of family planning in women of urban and rural areas. The findings of the study revealed that $43.8 \%$ of women in urban and $42.4 \%$ in rural community had unmet needs of family planning. ${ }^{8}$

The present study revealed that highest unmet needs existed in the age group between 15 to 25 years i.e. (55.3\%) in the urban and (47.14\%) in the rural followed by age group revealed that unmet needs were highest among age group less than 20 years (38.2\%) followed by age group 21-25 years $(20.4 \%) .^{5}$

The present study showed the unmet needs were higher among the Hindus i.e. (78.94\% and $55.55 \%$ ) both in the urban and rural communities respectively than among Muslims i.e. (21.05\% and $44.44 \%$ ) respectively who lived with the nuclear families i.e. $(60.52 \%$ and $59.25 \%)$ respectively in both the urban and rural communities. The findings of the present study were supported by another study conducted bySudha V, Vrushabendra H, Srikanth S, Suganya E. measuring the proportion of unmet needs for family planning in urban and rural areas of Punducherry. The findings of the study revealed that unmet needs were majority $(71.5 \%)$ were Hindus and $78.7 \%$ belonged to nuclear family.Muslims were found to have less unmet needs for contraception than Hindus. ${ }^{9}$

\section{Conclusion}

The study showed that unmet needs were more among the urban women than the rural. Also, awareness was more in rural community as compared to urban areas. The practices of contraceptives methods were more in rural community than urban. The main reason for not using the contraceptives methods were fertility related, restriction from husband or self, contraceptive method related reasons and fear of side effects in both the communities. The mass media should be encouraged in community to the benefits of modern contraceptive methods. Health workers should educate the eligible couples for use of contraceptive 
methods in both urban and rural areas. Presence of unmet needs warrants an effective and intense health promotion program to encourage the uptake of contraceptives especially by women. The study was concluded with few recommendations to replicate on different setting, larger population and can be implicated in the field of nursing education, nursing practice, nursing administration and nursing research.

\section{Acknowledgement}

The authors acknowledge the efforts of administrators of both the urban and rural health care centers for their valuable opinion and guidance. Appreciation is also extended to all participants for their cooperation.

\section{Funding}

This is a self funded research.

\section{Conflict of Interest: None}

\section{References}

1. Valekar SS, Pandve HT, Chawla PS et al. Assessment of unmet needs of family planning and reasons for non-use of contraceptive methods among women in reproductive age in rural community. J Community Med Health Educ 2017; 7(4): 1-5.

2. Sapna P, Abdul RK, Narayan K. Unmet needs for contraception in married women in a tribal area of India. Malaysian journal of public health medicine 2010; 10(2): 44-51.

3. Sudarshan D, Ratikanta T, Bhaskar T et al. The pattern of unmet need of contraceptive use in married couples attending a tertiary care hospital in Eastern India. National Journal of Physiology, Pharmacy and Pharmacology 2018; 8(2): 192-196.

4. Bamgboye, Ajayi. Changing patterns of unmet needs of family planning among reproductive age in Nigeria. African Journal of Reproductive Health. 2016: Available at https://www.thefreelibrary.com/Changing+patterns+of+unmet+needs+for+family+planning+among+women+of...-a0468142368

5. Sachdeva A, Gupta A, Kumar D et al. Unmet need for family planning among married women of reproductive age group in rural and urban area of Shimla, India. International Journal of Medical Science and Public Health 2017; 6(9): 1372-1377.

6. Srishti S, Meenakshi K, Malik J et al. Assessment of unmet need for family planning and its determinants in a rural block of Haryana. Int J Community Med Public Health 2018; 5(5): 1968-1972.

7. Anthony, Igwegbe $\mathrm{O}$, Joseph et al. Prevalence and determinants of unmet need for family planning in South East Nigeria. International Journal of Medicine and Medical Sciences 2009: 1(8): 325-329.

8. Rujuta F, Neelam S. Does unmet need of family planning differ in women of urban and rural areas of central India. J Evolution Med Dent Sci 2018; 7(46): 5815-5820.

9. Sudha V, Vrushabhendra HN, Srikanth S et al. Unmet need for contraception among urban women, Puducherry. International Journal of Community Medicine and Public Health 2017; 4(5): 1494 -1499. 